\title{
EFFECTS OF STRAIN RATE AND TEMPERATURE ON THE MECHANICAL PROPERTIES OF GFRP COMPOSITES
}

\author{
J. L. V. Coelho ${ }^{\mathrm{a}}$, \\ and J. M. L. Reis ${ }^{b}$ \\ Universidade Federal Fluminense - UFF \\ Programa Francisco Eduardo Mourão Saboya \\ de Pós-Graduação em Engenharia Mecânica \\ Bairro São Domingos, Campus da Praia \\ Vermelha \\ CEP 24.210-240, Rua Passo da Patria, 156, \\ Niterói, RJ, Brasil \\ a,joaolvc@hotmail.com \\ bjreis@mec.uff.br \\ ABSTRACT \\ In this work, the mechanical response of a composite material based on glass \\ fibers embedded in an epoxy resin was experimentally studied as a function of \\ strain rate and temperature. It was shown that for the temperature range from \\ 23 to $100{ }^{\circ} \mathrm{C}$ the elastic properties of the composite are significant affected and \\ the strain rate influences only the ultimate strength. The experimental research \\ data and the approaches presented in this work should significantly extend our \\ knowledge of the effect of elevated temperatures on the mechanical behavior \\ of high temperature polymer matrix composites. \\ Keywords: composites, strain rate, temperature, mechanical properties.
}

\section{NOMENCLATURE}

The nomenclature section should list, in alphabetical order, all used symbols, their definitions and their unit, in alphabetical order, as in the examples below:

E elastic modulus, GPa

HDT heat distortion temperature, ${ }^{\circ} \mathrm{C}$

\section{Greek symbols}

$\varepsilon \quad$ strain rate, $\mathrm{s}^{1}$

$\rho$ density, $\mathrm{g} / \mathrm{cm}^{3}$

$\sigma \quad$ stress, $\mathrm{MPa}$

\section{INTRODUCTION}

Composite materials have been used to repair damaged gas and liquid transmission pipelines for more than a decade. Mechanical damage involving dents with gouges is one of the leading causes of transmission pipeline failures in terms of both static and cyclic pressure loading. Because of the severity of this defect type, pipeline companies are required torespond to these anomalies by either removing damaged sections or repair using welded sleeves. Since in some fields repair work cannot be performed using heat, composite materials gain a significant importance. Composite materials have been used to repair corroded pipelines and their use has gained wide acceptance across the pipeline industry. However, the mechanical responses of fiber- reinforced polymeric composites are sensitive to the rate at which they are loading and temperature operation. In many technological applications, under dynamic loading conditions, the response of a structure designed with static properties might be too conservative. The main reason is that mechanical properties of composites vary significantly with changing the strain rate and temperature. Unlike metals, which have been studied extensively over a wide range of strain rates and temperatures, only limited amount of information is available on the effects of strain rate and temperature on the response of fibrous composites.

Manu researchers studied composite materials at different strain rate and others have studied their behavior at different temperature but few combined both.

Rotem and Lifshitz (1971) investigated the tensile behavior of unidirectional glass fiber/epoxy composites over a wide range of strain rates from $10^{-}$ 6 to $30 \mathrm{~s}^{-1}$ and found that the dynamic strength is three times higher than the static strength and the dynamic modulus is $50 \%$ higher than the static modulus. However, while investigating angle ply glass/epoxy laminates, Lifshitz (1976) found that the elastic modulus and failure strain were independent on the strain rate and the dynamic failure stress was only 20-30\% higher than the static failure stress.

Tensile tests were performed on a glass epoxy laminate at different rates $\left(1.710-^{2}-2000 \mathrm{~mm} / \mathrm{s}\right)$ by Okoli and Smith $(1995,2000)$ to determine the effects of strain rate on Poisson's ratio (ratio of transverse strain to the corresponding axial strain below the proportional limit) of the material. 
Poisson's ratio was found to be rate insensitive. It was suggested that the rate insensitivity in Poisson's ratio of the laminates tested is due to the presence of fibers in the composites. The effect of strain rate on the tensile properties of a glass/epoxy composite was investigated by Okoli and Smith (1999) strain rate was attributed to the increased strength of the glass fibers with strain rate. In other studies the effects of strain rate on the tensile, shear, and flexural properties of glass/epoxy laminate was investigated by Okoli and Smith $(1995,1999,2000,2001)$.

Tensile modulus increased by $1.82 \%$, tensile strength increased by $9.3 \%$, shear strength increased by $7.06 \%$, and shear modulus increased by $11.06 \%$ per decade increase in log of strain rate. The above observation was in agreement with the results of the investigation conducted by Armenakas and Sciamarella (1973) that suggested a linear variation of the tensile modulus of elasticity of unidirectional glass/epoxy composites with the log of strain rate.

A systematic study of the strain rate effects on the mechanical behavior of glass/epoxy angle ply laminates was done by Staab and Gilat $(1993,1995)$ using a direction tension split Hopkinson bar apparatus for the high strain rate tests and a servo hydraulic testing machine for the quasi-static tests. The tensile tests at higher strain rates (in the order of $1000 \mathrm{~s}^{1}$ ) showed a marked increase in the maximum normal stress and strain when compared to the values obtained in the quasi-static tests. Although both fibers and matrix are strain rate sensitive, the fibers were thought to influence laminate rate sensitivity more than the matrix.

To achieve the high performance required in the material's projected applications, a good understanding of the dynamic deformation of GFRP under different temperatures is essential. The aim of this paper is first to present experimental results illustrating the effect of strain rate and temperature on the mechanical response for GFRP under a wide range of strain rates and temperatures and then compare to analytical models.

\section{EXPERIMENTAL WORK}

The apparatus and procedure used to obtain the tensile properties in the GFRP laminates are described below.

The tensile tests were performed according to the method prescribed in ASTM D3039 [13]. The test specimens were cut from hand lay-up sheets. The glass was a cross-ply plain weave e-glass [0/90] fabric with $326 \mathrm{~g} / \mathrm{cm} 2$ weight. The composite had a fiber weight fraction of $70 \%$ with 8 layers of glass. The epoxy resin system used was RR515 from SILAEX ${ }^{\circledR}$ based on a diglycidyl ether bisphenol A and an aliphatic amine hardener, being processed with a maximum mix ratio of $4: 1$ (with low viscosity). The resin systems properties provided by the manufacturers are presented in Table 1.
Table 1. Properties of the epoxy resin.

\begin{tabular}{|c|c|}
\hline Property & Epoxy \\
\hline Viscosity at $25^{\circ} \mathrm{C} \mu(\mathrm{cP})$ & $12000-13000$ \\
\hline Density $\rho\left(\mathrm{g} / \mathrm{cm}^{3}\right)$ & 1.16 \\
\hline $\begin{array}{c}\text { Heat Distortion Temperature } \\
\text { HDT }\left({ }^{\circ} \mathrm{C}\right)\end{array}$ & 50 \\
\hline Modulus of Elasticity E $(\mathrm{GPa})$ & 5.0 \\
\hline Flexural Strength $(\mathrm{MPa})$ & 60 \\
\hline Tensile Strength $(\mathrm{MPa})$ & 73 \\
\hline Maximum Elongation $(\%)$ & 4 \\
\hline
\end{tabular}

The specimens were cut $250 \mathrm{~mm}$ by $25 \mathrm{~mm}$, leaving a gauge section of $200 \mathrm{~mm}$. The tensile tests were performed on a Shimadzu AG-X tensile testing machine at 3 different strain rates, $1.6 \times 10^{-5} \mathrm{~s}^{-1}$, and $1.6 \times 10^{-4} \mathrm{~s}^{-1}$ e $1.6 \times 10^{-3} \mathrm{~s}^{-1}$. Attached to the testing machine a thermostatic chamber was used to set the temperature test environment, as shown in Fig. 1. The test temperature used were, $23^{\circ} \mathrm{C}, 40^{\circ} \mathrm{C}, 60^{\circ} \mathrm{C}, 80^{\circ} \mathrm{C}$ and $100^{\circ} \mathrm{C}$. For each temperature the GFRP specimens were tested at all strain rates.

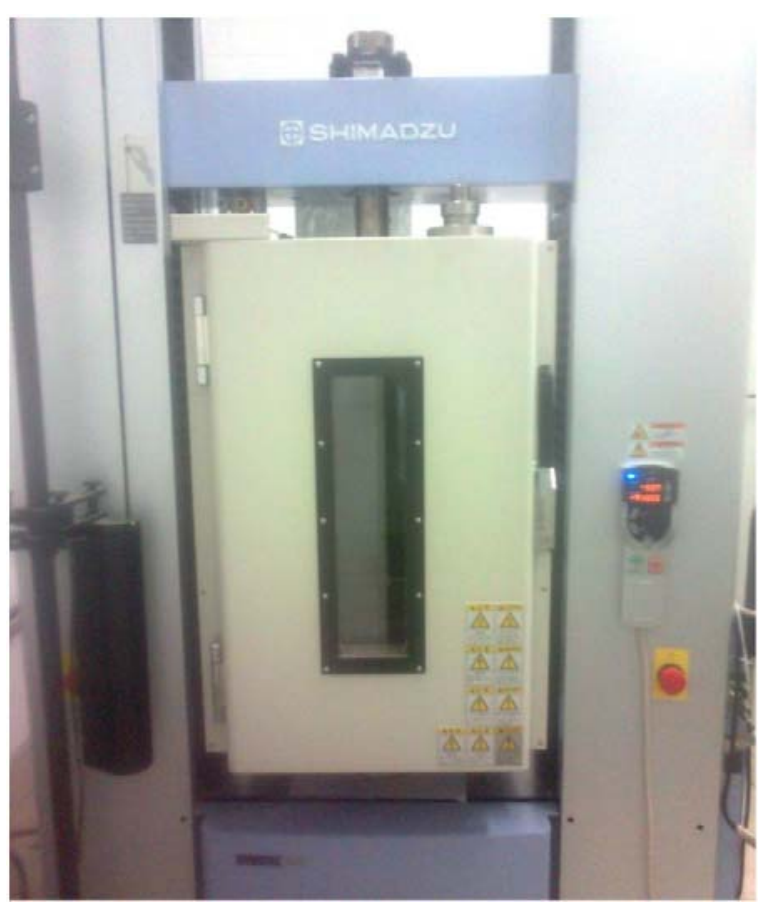

Figure 1. Machine used in the tensile tests.

\section{RESULTS AND DISCUTION}

\section{EXPERIMENTAL RESULTS}

Experimental data determining the dynamic response of a composite structure loaded at different strain rates is limited by the range of strain rates which can practically be applied for a particular test method. It is desirable to obtain information about strain rates outside the range that can be achieved 
experimentally, in order to predict the behavior of materials over very long loading times.

Figure 2 presents the stress vs. strain results of GFRP at different temperatures and at different strain rates.

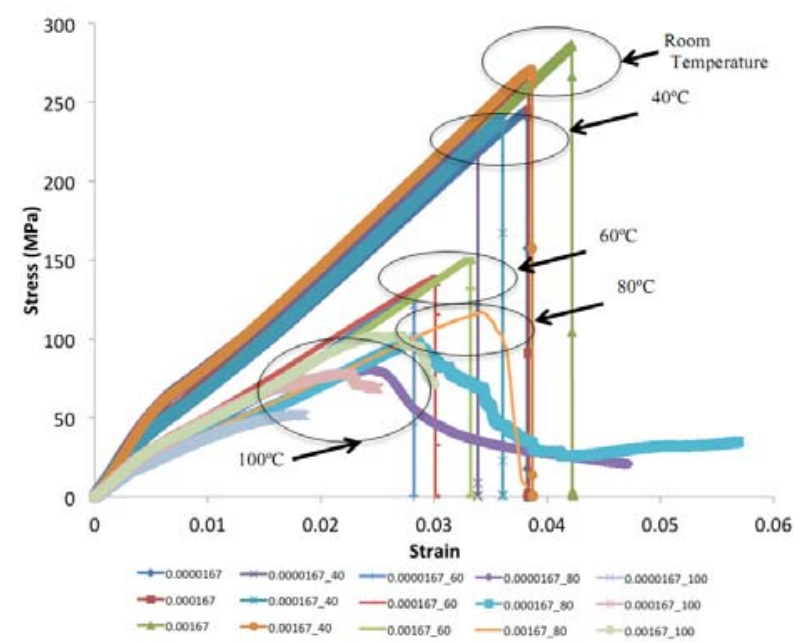

Figure 2. Stress vs. strain curves for GFRP at different temperatures at $1.6 \times 10^{-5} \mathrm{~s}^{-1}, 1.6 \times 10^{-4} \mathrm{~s}^{-1} \mathrm{e}$ $1.6 \times 10^{-3} \mathrm{~s}^{-1}$.strain rates.

Analyzing the stress-strain curves presented in Fig. 2 it is clear that, as expected, temperature influences the modulus of elasticity, E, and the ultimate strength, ou are affected by the strain rate. Increasing temperature, modulus of elasticity decreases and lower strain rate contributes to lowering the ultimate strength. All GFRP specimens failed abruptly at the top near the grip. However, GFRP specimens when tested at $100^{\circ} \mathrm{C}$ the epoxy matrix melted occurring in delamination failure. This phenomenon result in an increment of stiffness, see Figure 1.

Table 2 presents the ultimate strength in MPa of GFRP at different temperatures at $1.6 \times 10^{-5} \mathrm{~s}^{-1}, 1.6 \mathrm{x}$ $10^{-4} \mathrm{~s}^{-1}$ e $1.6 \times 10^{-3} \mathrm{~S}^{-1}$.strain rates.

Table 2. Ultimate Strength $(\mathrm{MPa})$ at different temperatures $1.6 \times 10^{-5} \mathrm{~s}^{-1}, 1.6 \times 10^{-4} \mathrm{~s}^{-1}$ e $1.6 \times 10^{-3} \mathrm{~s}^{-1}$ strain rates.

\begin{tabular}{|c|c|c|c|c|c|}
\hline $\begin{array}{c}\text { Strain } \\
\text { Rate } \\
\left(\mathrm{s}^{-1}\right)\end{array}$ & \multicolumn{5}{|c|}{ Temperature $\left({ }^{\circ} \mathrm{C}\right)$} \\
\cline { 2 - 6 } & 20 & 40 & 60 & 80 & 100 \\
\hline \multirow{2}{*}{0.0000167} & 227.4 & 214.9 & 113.4 & $72.6 \pm$ & 48.7 \\
& \pm 12.4 & \pm 12.7 & \pm 11.8 & 7.1 & \pm 4.8 \\
\hline \multirow{2}{*}{0.000167} & 269.23 & 240.44 & 141.85 & 86.21 & 71.54 \\
& \pm 15.9 & \pm 4.32 & \pm 4.96 & \pm 1.23 & \pm 8.1 \\
\hline \multirow{2}{*}{0.00167} & 284.9 & 273.2 & 153.6 & 101.6 & 102.6 \\
& \pm 5.1 & \pm 5.8 & \pm 3.4 & \pm 10.4 & \pm 6.6 \\
\hline
\end{tabular}

From Table 2 it is seen that at higher loading rate leads to high ultimate strength. At $23^{\circ} \mathrm{C}$, laboratory temperature, a decrease of $15.5 \%$ is observed when loading rate decreases 10 times compared to standard cross-head speed. Also an increase of $5.8 \%$ is computed for 10 times higher loading rate. This behavior follows all tested temperatures, i.e., increasing loading rate, higher ultimate strength and the opposite occurs for loading rate decrement.

The Figure 3 presents the ultimate tensile strength vs. test temperature for all strain rates.

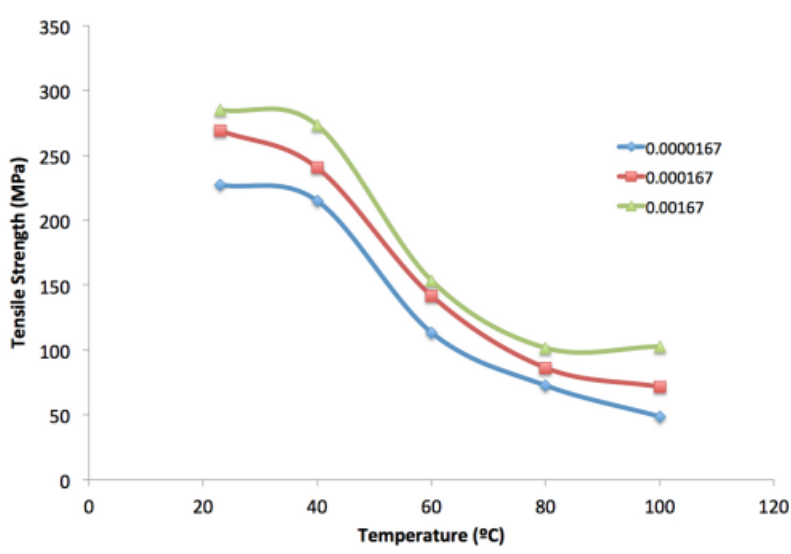

Figure 3. Tensile strength vs. test temperature for all strain rates.

Analyzing the Fig. 3, it can be seen that increasing temperature the ultimate tensile strength decrease drastically, especially at temperatures close to $\mathrm{HDT}, 50^{\circ} \mathrm{C}$. The tensile strength behaves similar for all strain rates tested, lowering as temperature increases.

\section{CONCLUSIONS}

This research presents uniaxial tensile tests of glass fiber epoxy polymer matrix composite with various strain rates and temperatures ranging from 23 to $100^{\circ} \mathrm{C}$.

Tests performed at $100^{\circ} \mathrm{C}$, showed a delamination between composite layers, causing a less brittle behavior and indicating that the specific heat of the material was exceeded.

The ultimate tensile stress depends only on strain rate and the modulus of elasticity is determined by temperature distinct.

Experimental tests have showed satisfactory results and are highly relevant to study the effect of elevated temperatures on the mechanical behavior of polymer matrix composites. It is also proved to be interesting to perform further studies to formulate a mathematical model that can accurately express the results obtained in the experiment and still be able to compare through a finite element analysis FEA. 


\section{ACKNOWLEDGEMENTS}

The financial support of FAPERJ (Rio de Janeiro State Funding), CNPq (Research and Teaching National Council) and CAPES (Coordination of Improvement of Higher Level Personnel) are gratefully acknowledged.

\section{REFERENCES}

Armenakas, A. E. and Sciammarella, C. A., 1973, Response of glass-fiber-reinforced epoxy specimens to high rates of tensile loading, Experimental Mechanics, Vol. 13, No. 10, pp.433440.

Lifshitz, J. M., 1976, Impact strength of angle ply fiber reinforced materials, Journal of Composite Materials, Vol. 10, pp. 92-101.

Okoli, O. I. and Smith, G. F., 1995, Overcoming Inertial Problems in the high strain rate testing of a glass/epoxy composite, Proceedings of Society of Plastics Engineers Annual Technical Conference (ANTEC), Advanced Polymer Composites Division, Vol. 2, pp. $2998-3002$.

Okoli, O. I. and Smith, G. F., 2000, The effect of strain rate and fibre content on the Poisson's ratio of glass/epoxy composites, Composite Structures, Vol. 48, pp. 157-161.

Okoli, O. I. and Smith, G. F., 1999, Aspects of the tensile response of random continuous glass epoxy composites, Journal of Reinforced Plastics and Composites Vol. 18, pp. 606-661.

Okoli, O. I., 2001, The effects of strain rate and failure modes on the failure energy of fibre reinforced composites, Composite Structures, Vol. 54, pp. 299303.

Rotem, A. and Lifshitz, J. M., 1971, Longitudinal strength of unidirectional fibrous composite under high rate of loading, Proceedings of the 26th annual technical conference, society for plastics industry, reinforced plastics/composites division, Washington, DC, Section 10-G. p. 1-10.

Staab, G. H. and Gilat, A., 1995, High Strain Rate Response of Angle-Ply Glass/Epoxy Laminates, Journal of Composite Materials, Vol. 29, No. 10, pp. 1308-1320.

Staab, G. H. and Gilat, A., 1993, High Strain Rate Characterization of Angle-Ply Glass/Epoxy Laminates, Proceedings of the 7th International Conference on Composite Materials, ICCM 7th, Madrid, Spain, Vol. 29, pp. $278-285$.

Received: July 30, 2011

Revised: August 30, 2011

Accepted: September 30, 2011 